\title{
Endocrine milieu and erectile dysfunction: is oestradiol- testosterone imbalance, a risk factor in the elderly?
}

\author{
Balasubramanian Srilatha and P Ganesan Adaikan
}

Oestrogens are not exclusive to the female gender but occur in moderate circulating levels of $25-70 \mathrm{pg} \mathrm{ml}^{-1}$ in men, compared to $44-$ $153 \mathrm{pg} \mathrm{ml}^{-1}$ in women. Arising from aromatisation of testosterone (T), oestrogen is considered to have many opposing physiological functions and the progressive $T$ decline in the aging male is associated with relative and/or absolute increase in serum oestradiol ( $\left.E_{2}\right)$. Sexual disinterest and erectile dysfunction (ED) in the elderly may well be due to pathophysiological $\mathrm{E}_{2}-\mathrm{T}$ imbalance; the altered hormonal ratio may also explain the higher incidence of ED in hyperestrogenism or following exposure to environmental/plant oestrogens. Asian Journal of Andrology (2011) 13, 569-573; doi:10.1038/aja.2010.129; published online 21 March 2011

Keywords: aging; erectile dysfunction; hormone imbalance; oestradiol; phytoestrogen; testosterone

\section{INTRODUCTION}

The last two decades have witnessed the change in the scientific outlook of erectile dysfunction (ED) which is now regarded as a multifactorial and predominantly an organic disorder. Since the erectile process is a coordinated function with neurologic, vascular, endocrine and ionic inputs, successful therapeutic outcome for ED envisages recognition and delineation of the precipitating causes. An important premise is the increased prevalence of ED with aging ${ }^{1}$ coupled with the possibility that the present population of men older than 65 years will double by the year $2025 .^{2} \mathrm{ED}$ in the elderly is a pertinent clinical issue.

Aging is associated with a number of comorbid conditions and risk factors for ED, including central and peripheral nervous system disorders, cardiovascular dysfunctions and side-effect profile of prescription medications. In addition to the wide range of general physical complaints in the elderly, it is imperative to address age-related affective alterations arising possibly from hormonal and lifestyle adjustments. ${ }^{3}$ With the multifactorial symptoms and evidence for the missing correlation of testosterone $(\mathrm{T})$ levels in the clinical features of hypogonadism, ${ }^{4}$ further complexities have to be considered. For instance, not all aging males present with sexual deterioration and in some, a non-hormonal background to the precipitating conditions affecting sexuality may coexist. These include depression, fragility, decreased vitality, endothelial dysfunction, chronic diseases, cancer, incontinence, cognitive impairment and concurrent problems of the aging partner. At the cellular level too, decreased expression and activation of endothelial nitric oxide (NO) synthase with aging and the subsequent blunting of the physiological actions of NO, may have a non-hormonal basis. Therefore, caution should be used while associating hormonal, particularly oestradiol $\left(\mathrm{E}_{2}\right)-\mathrm{T}$ imbalance, to ageassociated ED.

Nevertheless, steroid hormone secretion conforms to overall health status in men and understanding the dynamics of endocrine modulation is important in appreciating the role of hormones in sexual and reproductive function. Although an inverse correlation of androgen milieu with age was reported in the fifties, ${ }^{5}$ the initial indications of declining plasma $\mathrm{T}$ levels in elderly men were not supported by later studies. However, the inconsistent findings were attributed to technical or methodological problems and better-controlled studies indeed confirmed the total and free $\mathrm{T}$ levels to decrease considerably with age together with an increase in sex hormone-binding globulin. ${ }^{6}$ Therefore, notwithstanding the inherent limitations, standardized $\mathrm{T}$ assays have been relied upon to provide better diagnostic criteria and improved management options for suspected hypogonadal states. ${ }^{7}$ Given the wide normal range for $\mathrm{T}$, interpersonal and target tissue level variations and lack of a dramatic male climacteric, it is conceivable that $\mathrm{T}$ supplements may not improve all the presenting problems in the majority, including those of sexual dysfunction.

A concurrent endocrine change in the aging male is the relative and/ or an absolute increase in serum $\mathrm{E}_{2}$ level. ${ }^{8,9}$ Although $75-90 \%$ of this 'female hormone' results from aromatisation of $\mathrm{T}$ in the steroid pathway in males, oestrogen is considered to be the other side of the coin, in counterbalance with $\mathrm{T}$ for its physiological effects. ${ }^{10}$ In congenital $\mathrm{E}_{2}$ inefficacy/deficiency from oestrogen receptor (ER) gene and aromatase cytochrome P450 gene mutations, endogenous deficiency of oestrogen-specific physiological responses was seen as continued linear growth, unfused epiphyses, osteoporosis and infertility. Furthermore, these subjects had elevated follicle-stimulating and luteinizing hormone levels in the presence of normal or elevated $\mathrm{T}$ due to lack of oestrogenic feedback regulation on gonadotropin secretion. ${ }^{11}$ On the other hand, Klinefelter's syndrome (a 47,XXY karyotype) and feminizing tumour of the adrenal cortex are cases of oestrogen excess and androgen deficiency with gynaecomastia, diminished libido, erectile impairment and testicular and prostatic atrophy. ${ }^{12,13}$ Testicular dysfunction, with features of hypogonadotropic hypogonadism, 
azoospermia and excessive $\mathrm{E}_{2}$, has been shown to respond to clomiphene citrate and gonadotropin-releasing hormone indicating thereby, that the abnormality of testicular steroidal pathway was essentially related to the oestrogenic excess. ${ }^{14}$ Other precipitating conditions of hyperestrogenism (and possible $\mathrm{T}$ deficiencies) include noninsulin-dependent diabetes mellitus, hypercholesterolaemia, chronic liver disorders, idiopathic haemochromatosis and tumours of male breast or Leydig cells. ${ }^{13,15-17}$

Obesity in males has been shown to be associated with low T levels, reduced spermatogenesis leading to infertility and a concomitant increase in the incidence of ED. ${ }^{18}$ Correction of hormonal imbalance (with increased total and free $\mathrm{T}$ and reduced prolactin levels) in the morbidly obese, resulting from substantial weight loss, improved erectile function quality as measured by International Index of Erectile Function scores. ${ }^{19}$ However, there are also some evidences for the $\mathrm{T}$ and $\mathrm{E}_{2}$ values not correlating with the clinical signs and symptoms of hypogonadism. ${ }^{4}$ Therefore, sexual compromise of the aging male should be considered to be multifactorial and not indiscriminately assigned to the age-associated $\mathrm{E}_{2}-\mathrm{T}$ imbalance.

The research question to address here is the possibility of oestrogens compromising endogenous androgen milieu and secondarily, sexual function-particularly from exposure to compounds of industrial (xeno-) and plant (phyto-) origin, which are structurally related to $\mathrm{E}_{2}{ }^{20}$ In the light of the existing knowledge, an in-depth understanding of the effects of exogenous oestrogen mimics on sexual parameters is needed to provide a rational understanding in this area. When this includes the paracrine endpoints of oestrogenic effect on the normal physiological principles of penile erection, it is possible to propose a basis for dysfunctional changes of hormone modulation in specific clinical presentations. In this review, we discuss the possible cross-talk of $\mathrm{T}$ with oestrogen and the male sexual health threats posed by the widely prevalent oestrogen mimics in the environment.

\section{ENDOGENOUS CROSS-TALK WITH OESTROGEN}

In the last two decades, clinical diagnosis of late-onset hypogonadism in the elderly has been based on the signs and symptoms of hormonal imbalance and the comorbid factors. While primary and compensated hypogonadism are a concomitant problem of aging, secondary hypogonadism may be correlated to obesity and such other, above-mentioned risk factors. ${ }^{21}$ Studies evaluating the basis of age-dependent changes in $\mathrm{T}$ levels have identified pathophysiological dysfunctions to be central, at the hypothalamo-pituitary axis, ${ }^{8}$ together with secondary changes in the testes, ${ }^{22}$ In a step-wise pattern, hypothalamic dysfunction will lead to downregulation of the anterior pituitary and decline in the levels of gonadotropins and $\mathrm{T}{ }^{8}$ In contrast to primary testicular failure due to gonadal pathology, the continued aromatisation to $E_{2}$ and the gonadotropin-suppressant effect of $E_{2}$ would modulate the ratio of free $\mathrm{T}$ to $\mathrm{E}_{2},{ }^{23,24}$ accompanied by further decrements in luteinizing hormone, follicle-stimulating hormone and T levels, ${ }^{8}$ and contribute to the age-related alterations in $\mathrm{E}_{2} / \mathrm{T}$ ratio and the decline of serum $\mathrm{T}$ levels.

Thus, the resultant endocrine imbalance in the male may have an impact on the parameters of sexual health including erectile function. As described by Basar et al. ${ }^{25}$ there appears to be a direct correlation of the elevated serum $\mathrm{E}_{2}$ to aging male symptom scores. It is therefore likely that the androgen deficiency may not be the sole cause for ED in the aging male. ${ }^{26}$ Literature evidence suggests that oestrogen is as effective as antiandrogen or gonadotropin-releasing hormone analogue in countering the hypersexuality of paraphiliacs ${ }^{27}$ and $\mathrm{E}_{2}$ can also rapidly reverse the idiopathic form of stuttering priapism ${ }^{28}$ - some anti-erectile effects of $E_{2}$ for our consideration. Similarly, $E_{2}$ supplementation prior to gender reassignment surgery reportedly feminized male transsexuals ${ }^{29}$ and this therapy over many months was essential for the development of breast and other female traits in these patients. In the process of such preoperative treatment, the prospective male-to-female transsexuals had observed gradual reductions in erectile and ejaculatory capacity, loss of nocturnal penile tumescence and morning erections. ${ }^{30}$ As such, oestrogenic influence on male sexual function may be either through its qualitatively antiandrogenic action or because of an alteration of the systemic $E_{2} / T$ ratio. It would be worthwhile to evaluate the two postulated mechanisms independently to yield the much-needed research evidence. No doubt, these attempts will have pertinent clinical implications in the diagnosis as well as management of impotence related to hormonal derangement, which makes up to $10-20 \%$ of the overall ED cases. $^{31}$

\section{UNDERSTANDING OESTROGEN EFFECTS IN THE MALE}

In the last decade, studies in castrated animals defined the changes in sexual behaviour following $\mathrm{T}$ withdrawal. While a low replacement dose of $\mathrm{T}$ completely restored erectile capacity, ${ }^{32}$ the mechanism of recovery appeared to be central as demonstrated by the fact that exogenous $\mathrm{T}$ facilitated apomorphine-induced erections in these rats. ${ }^{33}$ Furthermore, both oestrogen and androgen receptoral activities appeared to mediate the sexual behaviour through the posterodorsal nucleus of the medial amygdala in the brain of these castrated animals. ${ }^{34}$ Peripherally in the cavernosa, T restored nitrergic neurotransmission, accentuated NO synthase activity and promoted NO release with increments in the measured intracavernous pressure response. ${ }^{35}$ Together, it implies that T may have a dual physiological role, centrally on the libido and behavioural aspects and peripherally, as a comodulator of the erectile process.

Oestrogen is also known to have a battery of physiological effects in the male. At least, some of the originally described male hormonal effects are shown to be dependent on the peripheral (extra-testicular) and local (testicular) aromatisation of $\mathrm{T}$ to $17 \beta \mathrm{E}_{2}$ and oestrone. ${ }^{36}$ Together with the finding that oestrogens mediated specific biophysiological functions, attempts were made by researchers to locate the intracellular expression sites for ER in a number of male tissues. Using immunohistological and biochemical principles, the two ER subtypes $(\alpha, \beta)$ were identified in males and confirmed to bind with $E_{2}$ to modulate specific gene and protein expressions. ${ }^{37}$ Also, while centrally mediated aggressive behaviour was increased by ER- $\beta$ gene disruption in male mice, the sexual activity per se remained uninhibited. ${ }^{38}$ Similarly, preservation of ER- $\alpha$ effect was considered essential for normal intromission and ejaculatory function, ${ }^{39}$ together with the finding that propyl-pyrazole triol, an ER- $\alpha$ agonist and not diarylpropionitrile (ER- $\beta$ agonist) accentuated proceptive and receptive forms of sexual behaviour in female rats, ${ }^{40}$ Scientific evidence also indicates that ER mutations, which can occur normally in many tissue or cell lines, may have a specific impact on the altered actions. Furthermore, ER- $\alpha$ and ER- $\beta$ may occur together in same tissues colocalizing with androgen receptors ${ }^{11}$ to mediate a residual/net biological effect. Adding to this complexity then would be the non-genomic mechanisms resulting from cell surface interactions such as excitability of nerve or smooth muscle cell and movement of sodium, potassium and calcium ions; ${ }^{41}$ it is to be derived from these views that the oestrogenic tissue response in the males can be mediated in various ways. Together with the pioneering detection of ER- $\alpha$ and ER- $\beta$ within the cell nuclei of the penile corpus cavernosum, ${ }^{37,42}$ it becomes imperative 
to delineate the individualistic role of these receptors in the context of normal erectile process and in the aetiopathology and pathogenesis of ED.

In the light of available knowledge, we may be able therefore, to widen the horizons on the site-specific effects of oestrogens and understand the mechanism of response through the receptor subtype(s). Thus far, high aromatase activity and $\mathrm{E}_{2}$ concentrations have been demonstrated in parts of the male reproductive tract including rete testis, efferent ductules and sperms together with the possibility of ER upregulation following castration. ${ }^{43-45}$ Colocalisation of ER with androgen receptors in these tissues indicates that a functional antagonism in the physiological effects of oestrogen with $\mathrm{T}$ may be expected at these sites. Similarly, it is interesting to note that androgen receptors coexisted with ERs in the female clitoral cavernosum; ${ }^{46}$ considering these factors, it would be also worthwhile to delineate the rationale of the coexistence of receptors in either gender.

After early evidence for linking impotence with hyperestrogenism in the seventies, ${ }^{47}$ and the reported incidences of secondary hypogonadism and medical hypophysectomy following oestrogen administration, ${ }^{8}$ there is limited documentation for erectile impairment per se with $\mathrm{E}_{2}$. In some clinical trials, clomifene or tamoxifen citrates were successful in blocking the $\mathrm{E}_{2}$-mediated gonadotropin suppression. Indeed, a daily administration of clomifene citrate (100-200 mg per day) produced a twofold increase in serum $\mathrm{T}$, luteinizing hormone and follicle-stimulating hormone within a week. ${ }^{48}$ According to Guay et al., ${ }^{49}$ the above drug also improved sexual function in a group of ED patients presenting with hypogonadism and low T levels; however, there was no estimation of $\mathrm{E}_{2}$ level in that study. In our experience, a cohort of aged ED patients with complaints of sexual disinterest had significantly higher $\mathrm{E}_{2}$ (and low $\mathrm{T}$ ) levels after adjustment for age $\mathrm{e}^{50}$ and these patients responded minimally to therapeutic $\mathrm{T}$ supplements. Interestingly, Mancini et al. ${ }^{51}$ noted an elevated $\mathrm{E}_{2}$ as the only abnormality in a subset of ED patients. In another study too, long-term therapeutic efficacy of tadalafil in improving International Index of Erectile Function scores and sexual function was correlated to increase in $\mathrm{T} / \mathrm{E}_{2}$ ratio (resulting more from $\mathrm{E}_{2}$ decrease, rather than $\mathrm{T}$ increase).$^{52}$ There are also direct evidences from animal studies including dose-related inhibitory effect of intromission and postejaculatory mounting latencies by $\mathrm{E}_{2},{ }^{53}$ and reversal or normalisation of sexual function following $\mathrm{E}_{2}$ withdrawal. ${ }^{54}$ Taken together, it may be postulated that the opposing effects of androgen and oestrogen in sexual physiology may overlie a delicate 'yin yang' balance with the possibility of triggered cross-talk and functional derangement when the ratio is disturbed.

\section{OESTROGENIC PROVOCATION FROM THE ENVIRONMENT}

Over the last two decades, xenoestrogens have been shown to pose considerable threat to male reproductive function with declining semen quality and sperm counts. Although less potent than endogenous $\mathrm{E}_{2}$, they tend to accumulate in adipose tissue, thereby having longer half lives and potential for toxicity. ${ }^{55}$ It follows therefore, that the extent of biotoxicological effect of these chemicals will depend on the type and duration of such contact. In a clinical study, a group of industrial workers exposed to synthetic oestrogens (diethylstilbestrol and diaminostilbene) presented with loss of libido and ED. ${ }^{56}$

Hypothetically, it would appear that the systemic side effect of phytoestrogen isoflavones, which are consumed on a daily basis, may be of similar clinical relevance. As described in the literature, phytoestrogens are non-steroidal oestrogen mimics with conversion to active hormonal metabolites in the body; chemically these compounds may be phenolic or phenylpropanoic derivatives. ${ }^{57}$ Essentially, they may act as oestrogen agonists; however, they are also likely to be partial antagonists at the ER sites (mechanical blockade). The net biological effect would be a function of the amount consumed and converted to active principle, endogenous oestrogen level and receptor status and the actual site of action. ${ }^{58}$ Similar to xenoestrogens, phytoestrogens are weaker $\left(10^{-2}\right.$ to $\left.10^{-3}\right)$ compared to $17 \beta \mathrm{E}_{2}$. Furthermore, they may bind more selectively to ER- $\beta$ than ER- $\alpha$ and qualify as natural selective estrogen receptor modulators. ${ }^{59}$ Of noteworthy mention is their anti-androgenic effect in the male, which is mediated by the inhibited conversion of $\mathrm{T}$ to dihydrotestosterone (DHT) and accentuated synthesis of sex hormone binding globulin. ${ }^{60}$ Since these compounds circulate in higher free concentrations due to a lower affinity for extracellular binding proteins (sex hormone binding globulin and $\alpha$-fetoprotein), ${ }^{61}$ there is a strong possibility of their purported biological effects in males.

The soy proteins, which are widely present in Asian diets, have been shown to contain significant amounts of the phytoestrogen isoflavones, namely, daidzein and genistein. In the body, these compounds are easily conjugated to oestrogenic substances with considerable hormonal properties by the enzyme system in the gastrointestinal tract. ${ }^{62}$ The serum levels ( $\mathrm{ng} \mathrm{ml}^{-1}$ ) of isoflavones in question can be carefully measured by the standard technique of liquid chromatography-mass spectrometry and fluoroimmunoassay. ${ }^{63}$ Despite a low oral bioavailability, these agents have been demonstrated to reach three- to fivefolds higher target tissue levels ${ }^{64}$ with a potential for yet-to-beidentified clinical toxicity. Initial reports of the hormonal effects of soy isoflavones were based on the finding of active urinary metabolites in the Asian perimenopausal women presenting with fewer vasomotor symptoms. ${ }^{62}$ While their hormonal potency is a distinct advantage to women, the possibility of detrimental effect such as erectile impairment in the male counterparts, arising from similar exposure requires considerable attention. In animal studies, correlations have already been made between phytoestrogen intake, androgen decrease and ED. ${ }^{37,65-67}$ In the light of this evidence, it is important to bridge the lacunae in the understanding of this sexual health threat to men through well-designed epidemiological and prevalence studies.

\section{CONCLUDING REMARKS}

Scientific and clinical evidence points to the role of oestrogen as an interdependent risk factor for ED. Obviously, in many of the available reports, the accompanying $\mathrm{T}$ deficiency or its functional imbalance with $E_{2}$ presents as an inevitable comorbidity. Therefore, in addition to our attempts to delineate the mechanism of oestrogenic effects in male erectile function/dysfunction, constructing appropriate models of normal $\mathrm{T}$ levels in the presence of high circulating $\mathrm{E}_{2}$ may be useful in the evaluation of oestrogen per se as an independent risk factor for ED. The insight from such studies may prompt clinical trials with antiestrogens or aromatase inhibitors for a targeted management of oestrogen-mediated ED.

\section{FUTURE DIRECTIONS}

An adequate knowledge of the actual pathophysiological changes in sexual function with aging is essential to the primary care provider in determining an appropriate therapy. Most of the currently available data on oestrogen in males is in the form of clinical findings or case reports from small cohorts. Basic research into the physiologic mechanisms of erectile process coupled with elucidation of alterations or specific endocrine challenges of aging will undoubtedly optimize the therapeutic options for our ED patients. In the hitherto 
underexplored area of oestrogenic ED, studies that particularly evaluate its occurrence secondary to phytoestrogen intake would be valuable.

There is a moderate consumption of soy products in Asia and this issue has raised our concern about the potential adverse effects of these plant hormones with oestrogenic and antiandrogenic properties. The data collected will necessarily bridge the scientific void in knowledge related to prolonged phytoestrogen exposure. Such studies will also throw light on many issues of late-onset hypogonadism in the aging Asian males. Specifically, the clinical presentation, diagnosis and treatment of late-onset hypogonadism may differ from guidelines used in the West where the male androgen levels are not disrupted or distorted by ingestion of large amount of phytohormones on a daily basis. In a broader sense, our understanding may influence and alter Asian dietary habits for an overall improvement of the quality of life.

Furthermore, the risk association between dietary exposure and ED can also be expanded to include other correlations or variables such as severity and duration of dietary provocation, average daily intake, presence or absence of other comorbid conditions and specific drug use. In addition to yielding scientific information, the models established may be useful in investigations of specific clinical questions of 'andropause' and hypogonadism.

\section{COMPETING FINANCIAL INTERESTS}

The authors declare no competing financial interest.

1 Schiavi RC, Rehman J. Sexuality and aging. Urol Clin North Am 1995; 22: 711-25. 2 Tan KT. The use of anti-aging hormones: a review. Med Prog 2000; 27: 8-12.

3 Beutel ME, Wiltink J, Hauck EW, Auch D, Behre HM et al. Correlations between hormones, physical, and affective parameters in aging urologic outpatients. Eur Urol 2005; 47: 749-55.

4 Christ-Crain M, Mueller B, Gasser TC, Kraenzlin M, Trummler M et al. Is there a clinical relevance of partial androgen deficiency of the aging male? J Urol 2004; 172: 624-7.

5 Hollander N, Hollander VP. The microdetermination of testosterone in human spermatic vein blood. J Clin Endocrinol Metab 1958; 18: 966-70.

6 Feldman HA, Longcope C, Derby CA, Johannes CB, Araujo AB et al. Age trends in the level of serum testosterone and other hormones in middle-aged men: longitudinal results from the Massachusetts Male Aging Study. J Clin Endocrinol Metab 2002; 87: 589-98.

7 Rosner W, Vesper H, Endocrine Society, American Association for Clinical Chemistry, American Association of Clinical Endocrinologists et al. Toward excellence in testosterone testing: a consensus statement. J Clin Endocrinol Metab 2010; 95 : 4542-8.

8 Cohen PG. The role of estradiol in the maintenance of secondary hypogonadism in males in erectile dysfunction. Med Hypotheses 1998; 50: 331-3.

9 Oettel M. Is there a role for oestrogens in the maintenance of men's health? Aging Male 2002; 5: 248-57

10 Sharpe RM. Reproductive biology: do males rely on female hormones? Nature 1997; 390: 447-8.

11 Faustini-Fustini M, Rochira V, Carani C. Oestrogen deficiency in men: where are we today? Eur J Endocrinol 1999; 140: 111-29.

12 Veldhuis JD, Sowers JR, Rogol AD, Klein FA, Miller N et al. Pathophysiology of male hypogonadism associated with endogenous hyperestrogenism. Evidence for dual defects in the gonadal axis. N Engl J Med 1985; 312: 1371-5.

13 Heinig J, Jackisch C, Rody A, Koch O, Buechter D et al. Clinical management of breast cancer in males: a report of four cases. Eur J Obstet Gynaecol Reprod Biol 2002; 102: 67-73.

14 Valenta LJ, Elias AN. Male hypogonadism due to hyperestrogenism. N Eng/ J Med 1986; 314: 186

15 Thomas DB. Breast cancer in men. Epidemiol Rev 1993; 15: 220-31.

16 Stremmel W, Niederau C, Berger M, Kley HK, Kruskemper HL et al. Abnormalities in estrogen, androgen and insulin metabolism in idiopathic hemochromatosis. Ann NY Acad Sci 1988; 526: 209-23.

17 Mineur P, de Cooman S, Hustin J, Verhoeven G, de Hertogh R. Feminizing testicular Leydig cell tumor: hormonal profile before and after unilateral orchidectomy. J Clin Endocrinol Metab 1987; 64: 686-91.

18 Pasquali R, Patton L, Gambineri A. Obesity and infertility. Curr Opin Endocrinol Diabetes Obes 2007; 14: 482-7.

19 Reis LO, Favaro WJ, Barreiro GC, de Oliveira LC, Chaim EA et al. Erectile dysfunction and hormonal imbalance in morbidly obese male is reversed after gastric bypass surgery: a prospective randomized controlled trial. Int J Androl 2010; 33: 736-44.
20 Adlercreutz H, Mazur W. Phyto-estrogens and western diseases. Ann Med 1997; 29: 95-120.

21 Tajar A, Forti G, O'Neill TW, Lee DM, Silman AJ et al. Characteristics of secondary, primary and compensated hypogonadism in aging men: evidence from the European Male Ageing Study. J Clin Endocrinol Metab 2010; 95: 1810-8.

22 Magoha GA. Effect of ageing on androgen levels in elderly males. East Afr Med 1997; 74: 642-4.

23 Ferrini RL, Connor EB. Sex hormones and age: a cross-sectional study of testosterone and estradiol and their bioavailable fractions in community dwelling men. $\mathrm{Am} \mathrm{J}$ Epidemiol 1998; 147: 750-4.

24 Hess RA, Burnick D, Lee KH, Bahr J, Taylor JA et al. A role for estrogens in the male reproductive system. Nature 1997; 390: 509-12.

25 Basar MM, Aydin G, Mert HC, Keles I, Caglayan 0 et al. Relationship between serum sex steroids and Aging Male Symptoms score and International Index of Erectile Function. Urology 2005; 66: 597-601.

26 Srilatha B, Adaikan PG. Estrogen-androgen crosstalk in the pathophysiology of erectile dysfunction. Asian J Androl 2003; 5: 307-13.

27 Levitsky AM, Owens NJ. Pharmacologic treatment of hypersexuality and paraphilias in nursing home residents. J Am Geriatr Soc 1999; 47: 231-4.

28 Shamloul R, el Nashaar A. Idiopathic stuttering priapism treated successfully with low-dose ethinyl estradiol: a single case report. J Sex Med 2005; 2: 732-4.

29 Goh VH. A unique human model for the study of sex hormones and reproduction. Singapore J Obs Gyn 1999; 30: 1-8.

30 Jung GW, Hur GY, Kim DW, Yoon JH. Erectile function, histologic changes of the penis and testis according to long-term estrogen exposure. Int J Imp Res 2000; 12: S10.

31 Shabsigh R. Hypogonadism and erectile dysfunction: the role for testosterone therapy. Int J Impot Res 2003; 15(Suppl 4)S9-13.

32 Gray GD, Smith ER, Davidson JM. Hormonal regulation of penile erection in castrated male rats. Physiol Behav 1980; 24: 463-468.

33 Scaletta L, Hull E. Systemic or intracranial apomorphine increases copulation in longterm castrated male rats. Pharmacol Biochem Behav 1990; 37: 471-5.

34 Cooke BM, Breedlove SM, Jordan CL. Both estrogen receptors and androgen receptors contribute to testosterone-induced changes in the morphology of the medial amygdala and sexual arousal in male rats. Horm Behav 2003; 43: 336-46.

35 Zvara P, Sioufi R, Schipper HM, Begin LR, Brock GB. Nitric oxide mediated erectile activity is a testosterone dependent event: a rat erection model. Int J Imp Res 1995; 7: 209-19.

36 Merchenthaler I, Shughrue PJ. Estrogen receptor alpha versus beta: new estrogen responsive tissues and new potentials for HRT. In: Bellino FL, editor. Biology of Menopause. New York: Springer; 2000. pp259-72.

37 Srilatha B, Adaikan PG. Oestrogen and phytoestrogen predispose to erectile dysfunction: do ER-alpha and ER-beta in the cavernosum play a role? Urology 2004; 63: 382-6.

38 Nomura M, Andersson S, Korach KS, Gustafsson JA, Pfaff DW et al. Estrogen receptorbeta gene disruption potentiates estrogen-inducible aggression but not sexual behaviour in male mice. Eur J Neurosci 2006; 23: 1860-8.

39 Ogawa S, Washburn TF, Taylor J, Lubahn DB, Korach KS et al. Modifications of testosterone-dependent behaviors by estrogen receptor-alpha gene disruption in male mice. Endocrinology 1998; 139: 5058-69.

40 Mazzucco CA, Walker HA, Pawluski JL, Lieblich SE, Galea LA. ERalpha, but not ERbeta, mediates the expression of sexual behavior in the female rat. Behav Brain Res 2008; 191:111-7.

41 Miller G. Endocrinology: divorcing estrogen's bright and dark sides. Science 2002; 298: 723-4.

42 Dietrich W, Haitel A, Huber JC, Reiter WJ. Expression of oestrogen receptors in human corpus cavernosum and male urethra. J Histochem Cytochem 2004; 52: 355-60.

43 Fisher JS, Millar MR, Majdic G, Saunders PT, Fraser HM et al. Immunolocalization of estrogen receptor-alpha within the testis and excurrent ducts of the rat and marmoset monkey from perinatal life to adulthood. J Endocrinol 1997; 153: 485-95.

44 Hess RA, Bunick D, Bahr JM. Sperm, a source of estrogen. Environ Health Perspect 1995; 103: 59-62.

45 Bodker A, Andersson KE, Batra S, Juhl BR, Meyhoff $\mathrm{HH}$. The estrogen receptor expression in the male rabbit urethra and prostate following castration. Scand $J$ Urol Nephrol 1994; 28: 113-8.

46 Sadeghi-Nejad H, Moreland RB, Traish AM, Nehra A, Azadzoi KM et al. Preliminary report on the development and characterization of rabbit clitoral smooth muscle cell culture. Int J Impot Res 1998; 10: 165-9.

47 McSherry JA. Letter: estrogen and impotence. Can Med Assoc J 1976; 114: 1090-4.

48 Gooren LJ. Improvement of spermatogenesis after treatment with the antiestrogen tamoxifen in a man with the incomplete androgen insensitivity syndrome. J Clin Endocrinol Metab 1989; 68: 1207-10.

49 Guay AT, Jacobson J, Perez JB, Hodge MB, Velasquez E. Clomifene increases free testosterone levels in men with both secondary hypogonadism and erectile dysfunction: who does and does not benefit? Int J Impot Res 2003; 15: 156-65.

50 Srilatha B, Adaikan PG, Chong YS. Relevance of oestradiol-testosterone balance in erectile dysfunction patients' prognosis. Singapore Med J 2007; 48: 114-8.

51 Mancini A, Milardi D, Bianchi A, Summaria V, de Marinis L. Increased oestradiol levels in venous occlusive disorder: a possible functional mechanism of venous leakage. Int J Impot Res 2005; 17: 239-42.

52 Greco EA, Pili M, Bruzziches R, Corona G, Spera G et al. Testosterone:oestradiol ratio changes associated with long-term tadalafil administration: a pilot study. J Sex Med 2006; 3: 716-22. 
53 Adaikan PG, Srilatha B. Oestrogen-mediated hormonal imbalance precipitates erectile dysfunction. Int J Impot Res 2003; 15: 38-43.

54 Gill-Sharma MK, Dsouza S, Padwal V, Balasinor N, Aleem M et al. Antifertility effect of oestradiol in adult male rats. J Endocrinol Invest 2001; 24: 598-607.

55 Burnett AL. Environmental erectile dysfunction: can the environment really be hazardous to your erectile health? J Androl 2008; 29: 229-36.

56 Oliva A, Giami A, Multigner L. Environmental agents and erectile dysfunction: a study in a consulting population. J Androl 2002; 23: 546-50.

57 Brzezinski A, Debi A. Phytoestrogens: the 'natural' selective oestrogen receptor modulators? Eur J Obstet Gynecol Reprod Biol 1999; 85: 47-51.

58 Ginsburg J, Prelevic GM. Lack of significant hormonal effects and controlled trials of phytoestrogens. Lancet 2000; 355: 163-4.

59 Santti R, Makela S, Strauss L, Korkman J, Kostian ML. Phytoestrogens: potentia endocrine disruptors in males. Toxicol Ind Health 1998; 14: 223-37.

60 Sharma P, Wisniewski A, Braga-Basaria M, Xu X, Yep M et al. Lack of an effect of high dose isoflavones in men with prostate cancer undergoing androgen deprivation therapy. J Urol 2009; 182: 2265-72.
61 Cheek AO, McLachlan JA. Environmental hormones and the male reproductive system. J Androl 1998; 19: 5-10.

62 Setchell KD. Soy isoflavones-benefits and risks from nature's selective estrogen receptor modulators (SERMs). J Am Coll Nutr 2001; 20: S354-62.

63 Wang GJ, Lapcik O, Hampl R, Uehara M, Al-Maharik N et al. Time-resolved fluoroimmunoassay of plasma daidzein and genistein. Steroids 2000; 65: 339-48.

64 Janning P, Schuhmacher US, Upmeier A, Diel P, Michna H et al. Toxicokinetics of the phytoestrogen daidzein in female DA/Han rats. Arch Toxicol 2000; 74: 421-30.

65 Akingbemi BT, Braden TD, Kemppainen BW, Hancock KD, Sherrill JD et al. Exposure to phytoestrogens in the perinatal period affects androgen secretion by testicular Leydig cells in the adult rat. Endocrinology 2007; 148: 4475-88.

66 Pan L, Xia X, Feng Y, Jiang C, Cui Y et al. Exposure of juvenile rats to the phytoestrogen daidzein impairs erectile function in a dose-related manner in adulthood. $J$ Androl 2008; 29: 55-62.

$67 \mathrm{Hu} \mathrm{GX}$, Zhao BH, Chu YH, Zhou HY, Akingbemi BT et al. Effects of genistein and equo on human and rat testicular 3beta-hydr•oxysteroid dehydrogenase and 17betahydroxysteroid dehydrogenase 3 activities. Asian J Androl 2010; 12: 519-26. 